\title{
Human Factors and Mechanical Engineering for Defense and Safety: Welcome Message from Editors-in-Chief
}

\author{
Alexandre Papy ${ }^{1} \cdot$ Sebastien Roth ${ }^{2}$
}

Published online: 19 December 2016

(C) Springer Science+Business Media Singapore 2017

After years of research in fields where publishing in journals was, although sometimes possible, usually frustrating because rarely (never?) in the publication core topic, we are delighted to announce the launch of a new Springer journal entitled "Human Factor and Mechanical Engineering for Defense and Safety": HMDS.

We are pleased to provide to scientists, engineers, and industries a platform and opportunities to exchange about enhancements of tools, methods, and technologies in the field of defense and safety. The understanding of the mechanical behavior of the human body and protecting equipments are essential for police officers' or soldiers' safety. The need to explore defense and safety device to protect them against external loads, today more than ever, cannot be called into question.

The main objective of the journal is to promote all the topics of science which place the protection of human being in the center of interest. In this context, this platform offers a large range of topics, going from the development of new materials for protection, the understanding of physical loads and their interaction with the human body, going to standards testing or development of new equipments for safety, using today's experimental or numerical facilities.

HMDS benefits from an editorial board formed by worldwide reputation scientists, who all contribute to advancements of science in the field of defense technology. Research topics of these distinguished scientists are wide, which illustrate the large scope of the journal around engineering in defense and safety.

We wish the best for this journal and are confident that it will become a reference of knowledge-sharing platform for high quality research dedicated to defense or military-related applications. It will however not happen without the support of our so interesting scientific community. That is why we invite you to submit your work to HMDS. Together we will make it happen!

Editors-in-Chief

Alexandre Papy

Sebastien Roth
Sebastien Roth

sebastien.roth@utbm.fr

Royal Military Academy, Bruxelles, Belgium

2 University of Technology of Belfort-Montbéliard, Belfort, France 